\title{
Shadow as Trigger Factor of Morality Change in Utopian Society in the Novel From the New World
}

\author{
Muhammad Yandi \\ Balikpapan University \\ yandiynd113@gmail.com
}

\begin{abstract}
:
This research aims to analyze the role of shadow towards the morality change in a utopian society in the novel From the New World by Yusuke Kishi. There are two objectives of this research, they are to identify the factors of shadow within the novel and to find how shadow triggers morality change in utopian society within the novel. The theory used in this research is psychoanalysis by Carl Jung, specifically shadow and morality. Shadow was used to examine the atrocities conducted within the novel and Carl Jung's approach of morality was used to examine the morality change phenomenon in utopian society within the novel. The method used in this research is descriptive qualitative. The researcher found the factors of shadow as ego, personal unconscious, and dark aspects of personality. Each of these factors is integral in how shadow triggers morality change in utopian society and the resulting changes found are within social, sexual, and intuitive morality. The research shows that shadow is the primary cause of morality changes happening within the novel and this research aims to prove whether shadow could be repressed to achieve the perfect morality.
\end{abstract}

Keywords: Shadow, Morality Change, Utopian Society. 


\section{INTRODUCTION}

All humans possess the capability to commit crimes and misdeeds. This is a fact that encourages the establishment of law and any other safety measures within a society. Every society condemns crimes and social life in general sense condemns human misdeeds. However, humans are incapable to not have the urges and impulses that can be described as dark, disturbing or malicious. This is due to the fact that all humans possess shadow, the unknown, dark depths within the mind. Carl Jung (1970, p.77) elaborates that shadow is inseparable from every individual, and the more it is overlooked and denied, the stronger it would affect how said individuals achieve their interests. Jung (1981) also further stated that "the shadow is a living part of the personality and therefore wants to live with it in some form. It cannot be argued out of existence or rationalized into harmlessness" (p.36). Based on this definition, the researcher explains that shadow is inseparable part of personality that regulate humans' action and reaction of harms.

Therefore, due to its nature regarding harms, the existence of shadow is directly in opposition with morality. Morality is human conscience that dictates whether something is good or bad, which includes certain actions and thoughts. According to Carl Jung (1973), he stated that "morality is not imposed from outside; we have it in ourselves from the start - not the law, but our moral nature without which the collective life of human society would be impossible" (p.33). Hence, true morality is not forced by external factor but by each individual's initiative and it is one of the integral elements in sustaining human society.

The society's discouragement of shadow is one of the main points that can be analyzed in the novel From the New World. The idea of shadow is deeply affective within the society depicted in From the New World, forcing said society to completely change their perception of morality. The setting itself in From the New World is also depicted as a perfect world, a utopian society where everything must be in order, so the change of morality is encouraged to maintain that orderly state. According to The Oxford Dictionary of Phrase and Fable, utopia is "an imagined place or state of things in which everything is perfect. The word was first used as the name of an imaginary island, governed on a perfect political and social system, in the book Utopia (1516) by Sir Thomas More.

In the From the New World, the idea of shadow is the primary reason to change perception of morality in its various forms in order to create and uphold the utopian society that is the setting of the novel. The novel portrays how deep shadow could affect the people in utopian society throughout the course of the story, leading to change of morality. These changes are triggered by social pressure of shadow and the researcher is interested in discussing this theoretically as it discusses about the consequences and significance of human's evil qualities. The researcher would like to elaborate on this matter theoretically, analyzing whether this total change of societal morality is considered good or not, and whether shadow should be abolished completely. 


\section{LITERATURE REVIEW}

The theory used in this research is Carl Jung's psychology of literature theory, particularly psychoanalysis. This theory can be used to study the psychology within literary works, which has many issues concerning the human unconscious and behavior, as it encompasses many features that the human psyche possesses such as shadow archetype and morality. Therefore, psychoanalysis is used to identify factors of shadow that trigger morality changes found in the novel From the New World.

Carl Jung's psychoanalysis introduced the concept of archetype as a term to describe an assigned role of a human psyche that resembles a specific typing. Jung (1981, p.56) stated that archetype is closely related to collective unconscious because archetype is identified and shaped due to collective unconscious of an individual conforming the assigned role. These certain roles can be viewed as blueprint of human's thought pattern that resembles one another. Main archetypes that Carl Jung explores in depth are persona, shadow, anima $\&$ animus and self. Among these archetypes, shadow is the one that specifically revolves around the dark side of human nature and it is the main archetype that this research focuses on.

\section{Shadow}

Shadow is introduced by Jung as a system of relations between individual consciousness and carnal thoughts, fittingly likened as a shadow that always follows a person. Shadow is, as its name implies, is only a metaphorical imagery of a person's dark and twisted thoughts that is inseparable in mankind. The existence of shadow is inevitable and prevalent within each and every individual, whether the individuals are aware of it or not. Carl Jung pointed out his definition of shadow as follows:

"The shadow is a moral problem that challenges the whole ego-personality, for no one can become conscious of the shadow without considerable moral effort. To become conscious of it involves recognizing the dark aspects of the personality as present and real. This act is the essential condition for any kind of self-knowledge (Jung, 1979, p.20).

Based on this definition, the researcher regards that shadow presents a conflict of a person's ego-personality which can result in the creation of dark aspects of personality that are against the moral code or laws of society. Hence, the acknowledgement of shadow is vital to keep things in order, whether it be personally or socially.

In a sense, shadow is neither good or bad, but it is moral problem nonetheless. As shadow is inseparable, no individual is purely good but even so, 'evil' qualities such as anger, lust and such can also be beneficial drive. Shadow only gets to be social problem when it is unleashed irresponsibly and so, it is necessary to repress shadow behaviors to keep things in order.

There are numerous factors on how shadow could pose as societal morality problem, but the researcher has identified three most influential ones within the research object. Each factors of shadow are elaborated as below: 


\section{Ego}

Ego is the main component of human psyche within Jungian psychoanalysis. Ego is essentially important in the whole hierarchy of unconscious due that it functions as the base of human psyche that drives the individual to achieve to commit an act. The actions driven by ego, whether it is judged by personal or public opinion, could pose a conflict between the individual and individual, individual and society, or even individual and his own self. Jung provided his statement regarding the conflicts of ego as below:

"What drives people to war with themselves is the suspicion or the knowledge that they consist of two persons in opposition to one another. The conflict may be between the sensual and the spiritual man, or between the ego and the shadow" (Jung, 1970, p.253).

Based on this statement, the researcher considers that the clashing of opposing ego or between the ego and shadow could result in a conflict. In turn, it could potentially lead into many kinds of conflicts whether it is personal or societal scale conflict.

\section{Personal Unconscious}

Personal unconscious is something that every individual possesses, as every human is different in all sorts of way, particularly regarding the thought process. Understanding the reasoning behind the urge and thoughts, would provide an individual a sense of clarity and this also applies to how an individual acknowledges their shadow. The inevitability of shadow affecting thought processes is something that is need to be addressed, otherwise the shadow would pose as an overwhelming threat. Jung provided his statement in the matter as below:

"The shadow coincides with the "personal" unconscious (which corresponds to Freud's conception of the unconscious) ... The shadow personifies everything that the subject refuses to acknowledge about himself and yet is always thrusting itself upon him directly or indirectly-for instance, inferior traits of character and other incompatible tendencies" (Jung, 1981, p.265).

Based on Jung's statement, the researcher infers that the reason many individuals consider their shadow too unbearable to acknowledge is because it poses as the 'ugly truth' of said individual. This could pose as a risk because shadow is inevitable in nature and could overwhelm an individual if not addressed properly. The overwhelming urges presented by shadow, should it not be contained, would cause problematic acts that could be harmful personally or socially.

\section{Dark Aspects of Personality}

Personality within an individual has many layers. It changes accordingly by experience, knowledge and many other influential factors. The course where personality might develop is unpredictable and yields limitless potentials, not necessarily restricted in the scale of good or bad. Jung elaborates on the development of personality as below: 
Our personality develops in the course of our life from germs that are hard or impossible to discern, and it is only our deeds that reveal who we are. We are like the sun, which nourishes the life of the earth and brings forth every kind of strange, wonderful, and evil thing; (C. W. Jung Vol.17, 1981, p.159)

Based on this statement and Jung's use of metaphor, the researcher regards that every human possess countless possibilities of how personality could develop. Each individual equally possesses a chance to be good or evil, and committing said good or evil deeds.

Personality without a sense of self-restraint could dangerously resulted in having dark aspects. These dark aspects are the result of shadow overpowering the individual's personality. Dark aspects in personality could render an individual to revel in the evil qualities that every individual potentially possesses. These evil qualities are also varied in extent, with some individuals even capable to pose as being good while committing evil deeds, knowingly or unknowingly.

\section{Morality}

The idea of morality can be specified into many categories, but regardless of its forms it is deemed as one of the most influential aspect in the social life. Carl Jung (1973) defines morality as the instinctive regulator of action which also governs the collective life of the herd and can be found at all levels of society (p.33). The classification of morality is not strictly regulated by Carl Jung himself, as the concept of morality can be specified into many categories. However, the researcher compiled Carl Jung's statements regarding specific morality as below:

\section{Social Morality}

Social morality is morality regarding social life, laws and other components within becoming a member of social community and could also be regarded as normative morality, which is when the members of the society are expected to uphold what is 'normal' and socially accepted. Carl Jung (1977) states that "normative morality is identical with correct social morality, the sole proviso being that every individual must be free to modify social morality, not in accordance with his own caprice but in a manner he can defend before the tribunal of the eternal and inscrutable" (p. 385). Therefore, while an individual is expected to commit the correct social morality, it is decidedly free to interpret into manners especially within of thoughts of self.

\section{Sexual Morality}

Sexual morality is morality regarding the viewpoint of sexual matters which includes sexuality, sexual objectification, intercourse and such. Public persecution of sexual matters is prominent within any society as Carl Jung (1973) stated that "any form of love not sanctioned by law is considered immoral, whether between worth-while people or bounders" (p.33). Thus, while the conflicting viewpoint regarding sex is prevalent, any society is expected to uphold a certain legal stance of sexual matters in order to keep the society civilized. 


\section{Intuitive Morality}

Intuitive morality is morality that is personal and separate within each individual. According to Carl Jung (1971), the intuitive morality is governed neither by thinking nor by feeling as it has its own characteristic morality, which consists in a loyalty to his vision and in voluntary submission to its authority (p. 354). Therefore, intuitive morality is morality that is personal views and thoughts within an individual that are subservient to a form of authority, whether it be law or an individual's own choice.

\section{Utopia}

Utopia is an idea or state of environment that is flawless in any sort of forms. Napier (1996) defined utopia as a place of ideal place of perfection, especially in law, government and social condition (p.43). Within general and broader definition, utopia also refers to a perfect society and this is the definition that the researcher abides in this research. The term utopian is used to refer a world or environment that is perfect in terms of political, social, material and economical aspect.

\section{RESEARCH METHODOLOGY}

In this research, the researcher first collected the data from the novel From the New World and supporting references regarding relevant theory. The researcher further identified the descriptive data that are relevant to the theories to conduct the analysis and interpretation. This research focuses on factors of shadow and how these factors could trigger morality change in utopian society as depicted in From the New World. The researcher used the qualitative descriptive method because the source of data of this research is a novel that requires deep understanding of what the implications within the novel are that further be presented in the analysis in the form of description.

\section{FINDINGS AND DISCUSSION}

The findings collected by the researcher are data regarding factors of shadow; ego, personal unconscious and dark aspects of personality. Each of these factors are influential in terms of how an individual perceives and treat their shadow archetype. Furthermore, in order to identify the morality changes, the researcher must first describe how shadow trigger the morality change and how each changes correlate to utopia.

\section{Factors of Shadow}

In this discussion section, the researcher explains about the factors of shadow found in the From the New World. The deciding factors of how shadow is treated or acted upon are numerous, but the researcher identifies that ego, personal unconscious and dark aspects of personality are among them. The factors of shadow itself already pose a dangerous risk and consequences for ordinary humans, so in the scenario where every human possess incredible powers, the threat itself increases tenfold. In this discussion, the researcher correlates the factors of shadow with the cantus (also called as psychokinesis or PK) power 
that mankind possesses in the novel as the catalyst for humans to commit the immoral acts of shadow behaviors.

1. Ego

In From the New World, human race is depicted as 'gods' for possessing incredible power of psychokinesis (dubbed as PK or cantus in-story). The researcher correlates power as influence that would bolster any individual's ego to achieve something. Hence, if every human possesses life-changing ability such as cantus, every humans' ego would also be tempted to have more needs and desires that transcend the mundane ones. Unchecked ego is one of the main reason for an individual to commit crimes and evil deeds, and by definition, these are shadow behaviors.

"Yes. Following A's arrest, the number of crimes involving PK increased, but most went unsolved often because common methods of surveillance were rendered useless with PK. Normal people began attacking PK users as a whole, beginning with personal harassment and elevating to public abuse that nearly ended in executions. In defense, PK users formed their own factions and the most zealous of them proposed establishing a PK-exclusive society. Indiscriminate terrorism by PK users followed. The resulting political, ethical, and philosophical conflicts plunged the world into an age of violent discord. Without previous experience in this situation, there appeared to be no end to this world war." (p.80)

The excerpt above shows that cantus user abuse their power during the Dark Age, further causing global crisis of world war. Furthermore, it can be inferred that humans' ego to fulfil their needs drive cantus users to commit atrocious acts to achieve personal gains or defend themselves. The atrocities and violence that humans indulge in the Dark Age is horrendous. It is only possible because the existence of cantus allows humans to access the power to overcome the impossible.

"Why did you revolt against mankind, then?"

"Because we are not your slaves."

"What do you mean? Granted, we did ask you to pay tribute and to work for us, but we've always acknowledged your complete autonomy, haven't we?" Satoru said sharply.

"Only when you are in good humor, my masters. However, should we invoke your wrath for the tiniest of reasons, our colony would be instantly eradicated. Perhaps we are even less than slaves."

... "The elimination of a colony is the highest penalty. It's reserved for only the worst offenses. If you hadn't killed human beings, or revolted against us..."

I thought back on the past punishments the Exospecies Division had dealt out. "Which came first, the chicken or the egg? Either way, our lives are as uncertain as bubbles on the surface of a pond. Is it not natural to wish to escape that fate?" Yakomaru said, baring his teeth with his head held high. 
Prologue: Journal on Language and Literature Vol.6 No.2 (2020)

"We are highly intelligent beings. We are not inferior to you in any way. The only difference is you possess the wicked power called cantus, and we do not." (p.320)

The excerpt above shows that humans are arrogant and callous enough with their cantus power that they're willing to satisfy their needs by enslaving other discriminated race, which is queerats. In turn, queerats instigate rebellion to achieve their freedom. The researcher explains this as a display of ego fulfilment on both sides as humans enslave queerats to maintain privilege and enjoying convenience while queerats rebel in order to achieve equality and respect they feel they earned. Furthermore, human pride as a species also hinders their judgment and mistakenly consider their action as mercy and just, despite committing immoral slavery.

\section{Personal Unconscious}

The researcher correlates personal unconscious as factor of shadow due that there are things hidden in human mind that is not consciously known, which is shadow by definition. In the depths of the unconsciousness, intrusive thoughts may surface and depending on the individuals, these thoughts can be acted upon or repressed, but their emergence could never be fully controlled. This is one of the problems presented in the From the New World, as with cantus, humans can alter objects and their surroundings to limitless potential as their imagination permits and personal unconscious is highly influential to it.

No matter what people do, they can never completely control their mind. Even if they think they can control their conscious thoughts, they don't know what's going on in their subconscious. Our cantus is the most tangible manifestation of that."

... "For physical actions, there are multiple stages between forming an idea and completing it. Motive comes from our subconscious and must pass through our conscious mind before it can be realized, so logic and reason can change or stop an action from being taken. However, for our cantus, the inception and execution of an action is more or less simultaneous. Even if it's wrong, there's no time to correct it."

... there are still things hidden in the darkness of our subconscious." (p.222)

The excerpt above shows that cantus is deeply connected to the depth of human subconscious. From the darkness of subconscious, immoral intrusive thoughts may surface to the personal unconscious and this is a process that is natural and uncontrollable. This is a problem that can be solved by the individual's logic and reason to stop acting on these thoughts, but for humans with cantus, this is a difficult matter. The spontaneity nature of subconscious allow cantus user to influence their surroundings without the user's knowledge, and this is a problem if said cantus user thought of something immoral and despicable.

"There's a bottle of pills in there, filled with different types of poison. They gave it to me...

... "But they didn't work. It was too late. I guess it's easy to change poisons on a molecular level. Though I was surprised when even arsenic couldn't kill 
me. It seems like my shadow, the part of my unconscious that doesn't want to die, is capable of altering even basic elements." (p.227)

The excerpt above shows how cantus, driven by uncontrolled unconsciousness, act on its own against the user's intention. The user wishes to die because he is experiencing extreme cantus leak phenomenon that risks him turning into karma demon, but his cantus does not allow him to die by botching up his suicide attempt. Shadow is part of the unconscious that comprise human reaction to harm, both to self and to others, and in the excerpt above, it is stated that shadow directly correlates with cantus.

\section{Dark Aspects of Personality}

Every humans possesses dark aspects of personality as every individual has their own perception of good and bad. However, in From the New World, the existence of cantus proves challenging for humans to coexist with their dark aspects. Humans are subject of emotions such as anger, envy, pride and more. Combined with cantus, humans with overwhelming dark aspects in their personality would make a large scale societal problem. In the novel, humans with dominant and destructive dark aspects in their personality is called fiends and karma demons.

Until now, the birth of fiends and karma demons was seen as a spontaneous mutation. But according to the report, their appearance was clearly linked to the state of a society like that of ours ten years ago.

The theory, which at the moment is still mere conjecture, is that when many people in a society are subjected to high tension and other emotional disturbances, cantus leakage causes genetic mutation, creating a high chance of giving birth to children who have incomplete attack inhibition or death feedback.

On top of that, the report states that when the children are raised by emotionally unstable parents, the probability of them turning into karma demons skyrockets.

If that was really the mechanism for creating fiends and karma demons, then it made sense to worry because now was a more dangerous time than ever before. Ten years ago, our district was struck by an unprecedented tragedy. There were scenes of gruesome deaths that even now left many citizens traumatized. And in addition, the trauma caused by the war against the queerats, everyone felt at least a fleeting moment of hatred and desire for violence (p.487)

The excerpt above shows the possible link between society, environment and upbringing with the emergence of fiends and karma demons, cantus users with rampant shadow behaviors. Tension, trauma and emotional instability are among many other factors that could affect the development of an individual's personality into possessing the dark aspects.

The dark aspects of personality also could lead to the individual's tendency to commit shadow behaviors which opposes the morality. Hence, the society must change their sense of morality and make it integral within the daily environment in order to minimalize the 
emergence of shadow behaviors. In the novel, this is imperative because cantus users need to coexist without feeling threatened by the users that compulsively abuse their power.

Even normal humans, warm, friendly people leading fulfilling lives, can forget themselves in a moment of anger. Research indicates that ninety percent of peoples' stress comes from other people. How do you maintain a safe society if, in a split second of intense anger, you could easily rip off the head of the person in front of you?" (p.86)

The following excerpt is taken from false Minoshiro's explanation of the reasoning behind the creation of attack inhibition, a psychological system to prevent emergence of fiends and karma demons. The excerpt shows how anger and aggression is a natural response within any individuals and thus, inevitable to fully prevent no matter how patient and morally decent a person is. It is based on this problem that the attack inhibition is considered necessary by the new society of cantus users, which is to prevent anyone from unleashing their cantus power aggressively in moments of anger.

\section{Shadow Triggers Morality Change in Utopian Society}

The society depicted in From the New World offers a different depiction of morality, because the society of Kamisu 66 is imagined as perfect and thus having perfect morality. Kamisu 66 operates on the basis of keeping eternal peace and making a perfect society without violence and dark thoughts. However, as shadow is stated to be inseparable, the threat of shadow behaviors still persists. The factors of shadow trigger the realization of shadow action, and in turn, the shadow itself triggers morality change, particularly in specific field such as social, sexual and intuitive morality.

\section{Social Morality Change}

In the novel, shadow behaviors emerging from cantus user fulfilling their ego becomes the primary challenge in maintaining the society. From the darkness of shadow, certain desires and needs may surface into the ego, giving the individual a choice to act on it or not. Considering not every dark desires is socially acceptable, this is when an individual's sense of morality obstruct the action to fulfil the ego.

"Saki, do you know what 'false obedience' means?"

I shook my head quietly.

"It means appearing to obey someone, but actually thinking the opposite underneath." "What do you mean by 'the opposite'?"

"Deceiving the other person, and secretly planning to betray them."

My jaw dropped. "People like that don't exist."

"You're right. People betraying other peoples' trust is impossible. But queerats aren't people."

For the first time, I felt the stirrings of fear.

"Queerats worship and obey us because we have cantus. But we don't know how they will behave toward children who've not yet awoken to their cantus. That's why we have to prevent queerats and children from meeting no matter what." (p.5) 
The excerpt above shows that humans has complete trust in each other, blatantly declaring anyone who would harm fellow humans is impossible to be found within the cantus user society. This statement shows the assurance of safety in living within Kamisu 66, removing the possibility of any crime happening. Thus, such perfection in safety can be classified as one of the characteristics of utopia.

However, the sentiment of safety and trust is not applied for queerats, despite they worship humans for having cantus power. This is because cantus users regard queerats as different species (despite they are intelligent, sentient and originally being humans themselves). Cantus users regard any species other as beneath them and they have certain pride of being humans blessed with cantus. Thus, this change of social morality cost human empathy in other species' welfare, allowing humans to further indulge ego.

Then, a thought came to me.

If we were to shut ourselves off from our senses, would we still be able to use our cantus?

Then, following that.

Why was it that there was nobody who had lost their sense of sight or hearing living in our town? (p.63)

The excerpt above shows the inexistence of anyone with sight or hearing disability within the society of cantus users. Considering cantus power require complete sense of its user, it can be inferred that the society of cantus users does not tolerate or excuse the existence of the disabled. The disabled are deliberately disposed in the same manner of handling potential threats, which is by killing through the use of tainted cats.

The towns are twisted.

Don't you think so? Can towns that kill their children to maintain peace and order be considered a normal human society? According to the false minoshiro, our history is one filled with bloodshed. However, I don't think our current society is any better than the dark ages of the past. Looking back on what happened in the towns, I am beginning to see what it is that warps it.

It is the adults' deep fear of all children.

Perhaps this has always been this case. It's obvious that seeing the next generation tear down everything you have struggled to build is difficult to accept, especially if it's your own children.

The way the adults of Kamisu 66 look upon their children is different, however. It's as if they are watching a row of eggs hatching, waiting anxiously to see if it is an angel, or, in a one in a million chance, a demon.

Based on intuition and premonition, hundreds upon thousands of eggs are smashed and discarded, and I refuse to be one of them. (p.299)

The excerpt above shows the protest of the safety system implemented by the society of cantus users. In effort of keeping peace, killing children is excused and even mandatory within the society of cantus users such as Kamisu 66. This has shown the drastic change of social morality demonstrated by this utopian society as it practices pedicide to maintain order. 
The drastic contrast of morality displayed in the novel is classified as social morality change because cantus users excuse discriminating inferior race, disposing the disabled and children with potential threats for the sake of maintaining their peaceful utopian society.

\section{Sexual Morality Change}

In From the New World, sexual morality is inevitably changed when cantus users made major altercation on human psychology in order to ensure survival. The society of cantus users, Kamisu 66, is depicted as perfectly peaceful due to the encouragement of free sex within the society. Sex is one of humans' primal needs and the liberation of its taboo is depicted in the novel as making a society more peaceful and in control.

"I have no data regarding the current state of society, so it is difficult to draw a comparison, but in the ancient civilization, there were numerous levels of taboo regarding physical contact. Also, in many places, homosexual love was forbidden and oppressed. Same with free sex."

For us, physical contact was a perfectly normal, everyday occurrence. Girls with guys, girls with girls, boys with boys, adults with adults, children with children, and adults with children. Basically, intimate contact between people was a good thing. The only exception being that any actions that might result in pregnancy; upon fulfilling certain conditions, a permit could be obtained from the Ethics Committee. (p. 87)

The excerpt above shows the drastic comparison between the ancient (real life) civilization with current society of cantus users in terms of sex taboo. In the society of cantus users, free sex is encouraged and even almost mandatory while in the past, it is regarded as taboo and moral violation. The encouragement of free sex is deliberately done to relieve tension, and it inadvertently makes the society peaceful as there is no more taboos about pleasure.

The researcher correlates sex with sexual morality because there are certain opposing reactions in real life toward free sex, homosexuality and pedophilia. Each society has their own perception of morality in sexual taboos and in the novel, free sex is depicted as beneficial and encouraged. This removal of sex taboos would be seen as unacceptable in today's society moral standard, particularly because it abolishes the taboos to the extreme extent. However, the encouragement of free sex depicted in the novel is caused by the necessity to alleviate shadow behaviors emergence.

\section{Intuitive Morality Change}

In From the New World, due to a number of psychological manipulations committed by cantus users to create a perfect utopian society, humans regress into a state that is highly different than standard perception. By having human mind manipulated, so does the intuitive morality would be changed. The change is reasoned by the necessity to create safe society that is free from evil, and yet violating human mind itself is already an immoral act. Thus, the intuitive morality is changed in order to fit the utopian image for cantus users' society where no humans could potentially harm each other and live in eternal peace.

"A ethologist called Konrad Lorenz who lived during the peak of the previous civilization said that powerful animals like wolves and ravens, as well as 
social animals, have an innate mechanism that causes them to avoid conflict with members of their own species. This is called attack control. On the other hand, physically weaker animals like humans and rats do not have as much control and tend to fight amongst each other, to the point of violent massacre. So if PK users are to live together in society, a powerful restraint on violence is essential." ( $\mathrm{p} .87)$

The excerpt above indicates humans' tendency to oppose one another and affinity to violent conflicts, which is encompassed within shadow and its correlating behaviors. In the novel, the urgency and importance to stop humans from killing each other urges the cantus user ancestors to rework not only the society, but also fellow humans. Cantus user need to possess powerful restraint to stop them from committing shadow behaviors and this restraint is the intuitive morality change, particularly in the form of death feedback or attack inhibition.

I admit that attack inhibition and death feedback have brought peace and order. But they are rigid, unnatural solutions that don't solve the real problem. Like a turtle with a crack in its shell, once your defenses are weakened, there's nothing you can do to stop the enemy from flooding in and laying waste. (p.488)

The excerpt above is taken from Saki's narration in the epilogue and it shows that death feedback does not present permanent or reliable solution to maintain peace. Death feedback might be considered as solution to maintain the impeccability of utopian society such as Kamisu 66, but it is not without fault. While death feedback presents moral stability in terms of humans fully trusting each other and incapable to do harms, it also presents fatal weakness in humans. Once a single fiend with wreaks havoc, the entire society could collapse as the society itself remove human capability to self-defense that shadow possesses.

Psychological manipulation is one of the primary reasons why the society of cantus users are peaceful and free of internal conflicts. There is no struggle for power, material wealth, pursue in pleasure, or any catalyst to commit crimes. Essentially, this also shows that the society of cantus users suppress their shadow in order to achieve this utopian state. However, there is no morality without freedom and the freedom of thought is removed within this utopian society, only selectively chosen to certain people in consideration to be the leaders. Hence, the researcher argues that the morality depicted in the novel is not true morality.

\section{CONCLUSION}

The researcher concludes that the extreme measures a perfect society would do to suppress shadow is already an act of imperfection itself. Though shadow is a natural opposition to morality, that does not mean it should be fully repressed. Shadow is irrevocable and integral part of mankind in terms of action and reaction to harms. Removing shadow completely means removing a significant part in human mind to act and react about danger 
and survival. In the novel, the morality change in utopian society is triggered by shadow, but the extreme absolution in morality changes themselves are apparent to be immoral, which is shadow behaviors by definition. Therefore, the researcher concludes that shadow is inevitable and impossible to be fully suppressed, let alone eliminated, and it is not advised to do so.

\section{References}

Jung, C.G \& Adler, G. (Eds.). (1970). Collected Works of C.G Jung, Volume 11: Psychology and Religion: West and East. Princeton, N.J: Princeton University Press

, C.G \& Adler, G. (Eds.). (1971). Collected Works of C.G Jung, Volume 6: Psychological Types. Princeton, N.J: Princeton University Press. , C.G \& Adler, G. (Eds.). (1973). Collected Works of C.G Jung, Volume 7: Two Essays on Analytical Psychology. Princeton, N.J: Princeton University Press.

, C.G \& Adler, G. (Eds.). (1977). Collected Works of C.G Jung, Volume 18: The Symbolic Life: Miscellaneous Writings. Princeton, N.J: Princeton University Press. , C.G \& Adler, G. (Eds.). (1979). Collected Works of C.G Jung, Volume 9 (Part 2): Aion: Researches into the Phenomenology of the Self. Princeton, N.J: Princeton University Press. , C.G \& Adler, G. (Eds.). (1981). Collected Works of C.G Jung, Volume 9 (Part 1): Archetypes \& Collective Unconscious. Princeton, N.J: Princeton University Press.

, C.G \& Adler, G. (Eds.). (1981). Collected Works of C.G Jung, Volume 17: Development of Personality. Princeton, N.J: Princeton University Press.

More, T. (1516). Utopia. Habsburg Netherlands: More.

Napier, Susan, J. (1996). The Fantastic in Modern Japan Literature: The Subversion of Modernity p.43. New York, London: Routledge. 